\title{
EFEKTIVITAS SOSIALISASI PERBANKAN SYARIAH MELALUI PROGRAM KOLOKASI DI BNI KLN IPB DRAMAGA
}

\author{
EFFECTIVENESS OF SOCIALIZATION ON BANK SHARIA THROUGH \\ THE COLLOCATION PROGRAM AT BNI KLN IPB DARMAGA
}

\author{
Mohamad Irsan Barkah Prawiradisastra*)1, M. Syamsul Ma'arif ${ }^{* *}$, Sadikin Kuswanto***) \\ ${ }^{*}$ BNI Syariah \\ Jl. Pajajaran Raya No. 63, Bogor 16151 \\ ${ }^{* *}$ Sekolah Bisnis, Institut Pertanian Bogor \\ Jl. Raya Pajajaran, Bogor 16151 \\ ${ }^{* * *}$ CDE Consulting Group \\ DKI Jakarta
}

\begin{abstract}
In the conduct of the socialization of sharia banking, BNI Sariah holds the collocation of letters carried out in BNI KLN IPB Dramaga. With the Collocation Program of BNI Sariah, we can see the effectiveness of socialization of sharia banking. The objectives of research are to analyze and to measure the impact of Brand awareness of BNI Sariah toward the effectiveness of BNI Sariah collocation program in BNI KLN IPB dramaga, to identify the dominant variable in determining the effectiveness of socializing of sharia banking, and to analyze the influence of Responsiveness of service officer of collocation program in BNI KLN IPB Dramaga. This research used quantitative analysis using the survey analyst to customers of BNI Sariah in BNI KLN IPB Dramaga and BNI Sariah Bogor and the analysis structural equation modelling (SEM). Based on the results of the analysis using the structural equation modelling (SEM), a conclusion can be taken from the study: collocation program is considered to have a positive and effective impact to increase the effectiveness of socialization of sharia banking that was carried out by BNI Sariah. Responsiveness is the dominant variable that supports the success of an effective socialization of BNI Sariah. Brand awareness also supports the socialization program, where BNI Sariah Brand is also well known among the public especially those who live in Dramaga.
\end{abstract}

Keywords: effectiveness, socialization, sharia banking, responsiveness, brand awareness, SEM

\begin{abstract}
Abstrak: Dalam melakukan sosialisasi perbankan syariah, BNI Syariah melakukan program kolokasi yang dilakukan di BNI KLN IPB Dramaga. Dengan program kolokasi BNI Syariah dapat melihat efektivitas sosialisasi perbankan syariah. Tujuan dari penelitian ini yaitu menganalisis dan mengukur pengaruh brand awareness BNI Syariah terhadap efektivitas program kolokasi BNI Syariah di Kantor Layanan (KLN) BNI IPB Dramaga, mengindentifikasi variabel indikator yang dominan dalam membentuk variabel brand awareness, menganalisis pengaruh daya tanggap (responsiveness) petugas kolokasi di KLN BNI IPB Dramaga terhadap efektivitas program, menganalisis variabel indikator yang dominan dalam membentuk variabel responsiveness atau daya tanggap. Penelitian ini menggunakan analisis kuantitatif dengan menggunakan survei terhadap nasabah BNI Syariah di BNI KLN IPB Dramaga. Penelitian ini menggunakan analisis Structural Equation Modelling (SEM). Hasil analisis dengan menggunakan SEM, kesimpulan yang dapat diambil dari penelitian ini, yaitu program kolokasi dinilai sebagai program yang sangat positif dan efektif dalam meningkatkan efektivitas sosialisasi perbankan syariah yang dilaksanakan oleh BNI Syariah. Responsiveness merupakan variabel yang dominan dimana petugas kolokasi dengan pengetahuan dan daya tanggap yang baik merupakan faktor penunjang keberhasilan efektivitas sosialisasi yang dilakukan BNI Syariah. Brand awareness juga menunjang sosialisasi perbankan syariah, dimana Branding BNI Syariah cukup dikenal masyarakat khususnya di sekitar BNI KLN Dramaga.
\end{abstract}

Kata kunci: efektivitas, perbankan syariah, responsiveness, brand awareness, SEM

\footnotetext{
${ }^{1}$ Alamat korespondensi:

Email: irsanbarkah@gmail.com
} 


\section{PENDAHULUAN}

Program kolokasi terbentuk atas keprihatinan dari manajemen BNI Syariah atas tidak tumbuhnya Dana Pihak Ketiga (DPK) di Sharia Channelling Outlet (SCO) serta untuk menahan dari hilangnya DPK syariah yang ada di BNI KLN IPB Dramaga. Program kolokasi adalah program penempatan petugas BNI Syariah di BNI untuk menjalankan fungsi sebagai marketing syariah dan juga sebagai petugas yang memastikan setiap kelengkapan marketing tools BNI Syariah tersedia dengan baik. Petugas kolokasi juga harus memastikan bahwa setiap front liner BNI memiliki pemahaman produk Syariah dengan baik.

Perbankan Syariah saat ini semakin dikenal oleh masyarakat Indonesia, Bank BNI Syariah adalah salah satu lembaga jasa keuangan syariah di Indonesia melihat akan tingginya kesadaran masyarakat untuk jasa keuangan syariah. Program kolokasi yang dibentuk oleh BNI Syariah ini bertujuan untuk membantu masyarakat dalam mendapatkan informasi mengenai jasa keuangan syariah.

Program kolokasi ini dilaksanakan di kantor BNI Konvensional di seluruh Indonesia dimana nasabah BNI dapat memperoleh informasi tentang perbankan syariah di kantor layanan BNI. Serta sebagai salah satu layanan yang dapat dinikmati oleh nasabah BNI Syariah yang ingin bertransaksi melalui BNI konvensional.

Kerjasama keagenan antara BNI dan BNI Syariah sejak berdirinya BNI Syariah terus mengalami kemunduran. Kemunduran tersebut adalah tidak dilayaninya transaksi BNI Syariah di BNI Konvensional oleh petugas BNI karena berbagai alasan. Kerja sama keagenan ini sangat menguntungkan bagi nasabah. Nasabah dapat memilih jenis transaksi antara konvensional dan syariah. Secara organisasi pegawai BNI Syariah merupakan pegawai organik dari Bank BNI sehingga secara otomatis antara antara BNI dan BNI Syariah tercipta hubungan timbal balik yang harmonis dan saling menguntungkan.

Sinergi antara BNI dan BNI Syariah akan dapat menjadikan keduanya unggul di mata masyarakat dan portofolio keuntungan yang lebih besar bagi grup BNI. Pada tahun 2010 tersebut pula tepatnya 19 Juni 2010 BNI Syariah resmi menjadi Bank umum syariah yang berarti BNI Syariah terpisah dari management Bank BNI Konvensional. Berdasarkan aturan dari Bank Indonesia yang mengatur mengenai Channeling Office,
BNI tetap mendukung kegiatan seluruh BNI nasabah BNI Syariah di seluruh cabang BNI dengan nama SCO. Program kolokasi ini dibuat untuk meningkatkan kesadaran masyarakat atas perbankan syariah dan juga sebagai problem solving bagi nasabah BNI Syariah.

BNI Syariah juga menempatkan petugasnya di lokasi kolokasi yang ditunjuk. Petugas Kolokasi BNI Syariah berkantor di KLN BNI Konvensional dan menjalankan fungsinya sebagai petugas pemasar serta sebagai penghubung komunikasi antara BNI Syariah dengan BNI Konvensional.

Pada awal berdiri BNI Syariah diawal tahun 2002, BNI Syariah hanya terdiri dari empat cabang Syariah. Namun, dengan dukungan penuh BNI dengan seluruh jaringan outlet-nya, BNI Syariah dapat tumbuh menjadi Bank yang sangat cepat perkembangannya. Nasabah BNI Syariah dapat dengan mudah memperoleh layanan Perbankan Syariah di seluruh outlet BNI, namun sejak BNI Syariah melakukan spinoff dari BNI pada tahun 2010, pertumbuhan Bisnis dari SCO mengalami stagnant bahkan cenderung menurun. Selama kurun waktu 2010 sampai dengan 2015 belum ada petugas khusus dari BNI Syariah yang ditempatkan di BNI. BNI Syariah hanya mengandalkan sistem kemitraan, yaitu SCO. Namun, sistem SCO tidak berjalan seperti yang diharapkan. Sejak BNI Syariah melakukan spinoff dari BNI, pertumbuhan dana pihak ketiga (DPK) di SCO tidak mengalami perubahan berarti.

Sejak tahun 2015, perkembangan dana BNI Syariah di SCO IPB Dramaga diduga terus mengalami penurunan yang signifikan. Atas adanya kendala tersebut, BNIPusat melalui Funds and Transactional Banking Divisoin (FTD) membuat kebijakan Kolokasi yaitu penempatan petugas Pemasar BNI Syariah dan melakukan Sosialisasi Produk BNI Syariah di BNI Konvensional yang ditunjuk. Dengan tujuan permasalahan yang terjadi di SCO seperti user iCon yang tidak aktif kemudian product knowledge dapat segera diatasi oleh Petugas Kolokasi. Petugas kolokasi harus mampu melakukan sosialisasi kepada front liner BNI, agar nasabah BNI Syariah nantinya dapat terlayani. Permasalahan spinoff antara BNI dan BNI syariah mulai menghadapi beberapa hambatan yang pada akhirnya menjadi permasalahan diantara keduanya. Adapun masalahmasalah yang teridentifikasi adalah nasabah yang tidak bisa membuka rekening Syariah di Kantor Layanan BNI Dramaga dikarenakan pengetahuan syariah dan transaksi syariah pada petugas BNI Dramaga yang 
diduga akan berdampak pada menurunnya transaksi syariah pada BNI Konvensional sehingga diduga DPK syariah tidak akan tumbuh.

Permasalahan spinoff antara BNI dan BNI syariah mulai menghadapi beberapa hambatan yang pada akhirnya menjadi permasalahan diantara keduanya. Tujuan dari penelitian ini adalah menganalisis dan mengukur pengaruh brand awareness BNI Syariah terhadap efektivitas program kolokasi BNI Syariah di Kantor Layanan (KLN) BNI Dramaga; mengidentifikasi variabel indikator yang dominan membentuk variabel brand awareness dan variabel responsiveness; menganalisis pengaruh daya tanggap (responsiveness) petugas kolokasi di KLN BNI Dramaga terhadap efektivitas program.

\section{METODE PENELITIAN}

Penelitian dilakukan di wilayah BNI KLN IPB Dramaga dan Kantor Cabang BNI Syariah Bogor. Penelitian terhadap efektivitas sosialisasi Perbankan Syariah dengan program Kolokasi dilakukan terhitung sejak bulan Juni 2015 sampai dengan Agustus 2016. Selama waktu penelitian ini penulis berupaya untuk dapat menjawab permasalahan dan sekaligus tujuan penelitian ini.

Dalam penelitian ini data yang digunakan yaitu data primer dan data sekunder. Data primer diperoleh melalui hasil instrumen Kuisioner yang disebar pada nasabah BNI Dramaga dan BNI Syariah Cabang Bogor yang pernah bertransaksi di BNI Dramaga. Data sekunder diperoleh dari database BNI Syariah serta buku pustaka yang memiliki relevansi dengan penelitian.

Pengumpulan data dilakukan melalui survei dengan menggunakan kuisioner sebagai instrumen utama penelitian, yang didukung oleh observasi sebagai instrumen penunjang atau pelengkap. Dengan digunakannya kuisioner sebagai metode pengumpulan data diharapkan penulis mendapatkan data yang relevan dengan tujuan dari penelitian, serta memperoleh data dengan reliabilitas dan validitas yang setinggi mungkin.

Pernyataan-pernyataan yang akan diberikan nasabah BNI Syariah pernyataan yang akan memberikan persepsi terhadap efektivitas keberadaan BNI Syariah melalui kolokasi. Pertanyaan akan dibuat secara kombinasi, yaitu pertanyaan tertutup dan pertanyaan terbuka. Pertanyaan terbuka akan meliputi data pribadi koresponden dan saran perbaikan dari koresponden. Pertanyaan tutup akan menggunakan skala Likert yang dalam menjawab pertanyaan kuesioner adalah dengan jawaban responden Sangat Tidak Setuju (STS) sampai Sangat Setuju (SS).

Teknik penentuan responden dalam penelitian ini menggunakan non probability sampling, dengan metode purposive sampling. Metode ini digunakan karena peneliti ingin mengambil sample khusus nasabah Bank BNI Syariah yang datang ke lokasi BNI KLN IPB Dramaga untuk menerima pelayanan dan juga Nasabah BNI Syariah di Cabang Bogor yang pernah bertransaksi di BNI Dramaga. Dalam penelitian ini jumlah sample yang akan diteliti sebanyak 4355 Number of Account (NOA) dimana jumlah ini mewakilkan jumlah nasabah dari BNI Syariah.

Dilihat dari jumlahyang demikian besar, maka penelitian ini akan menggunakan teknik sampling. Sample yang akan diambil akan diperhatikan aspek keterwakilannya. Maka dari itu dalam penentuan sample ini, peneliti akan menggunakan tehnik pengambilan sample yang diajukan oleh Slovin. Adapun tehnik ini menggunakan persamaan matematis yang disajikan:

$$
n=\frac{N}{1+N e^{2}}
$$

Keterangan: n (jumlah anggota sample); N (Jumlah anggota populasi); e (Tingkat kesalahan (error) yang dapat ditoleransi); tingkat kesalahan (error) yang dikendaki dalam peneleitian ini adalah sebesar $5 \%$, maka penggunaan teknik slovi untuk menghitung jumlah responden dalam penelitian ini adalah $\mathrm{n}=4355$ / $\left(1+4355 \times 0,05^{2}\right)=366$. Dari hasil perhitungan jumlah anggota sample dengan teknik slovin maka didapat sebanyak 366 jumlah responden.

Pendekatan penelitian yang digunakan adalah pendekatan kuantitatif dimana didasari oleh filsafat positifisme yang memandang setiap realitas, gejala, fenomena itu dapat diklasifikasikan, relatif tetap, konkrit, teramati, terukur, dan hubungan gejala bersifat sebab akibat. Dalam penyusunan tesis ini penulis menggunakan metode penelitian desrikptif menggambarkan sistem efektivitas sosialisasi perbankan syariah oleh BNI Syariah Cabang Bogor melalui program kolokasi di BNI Dramaga. Metode penelitian deskriptif digunakan utuk mengetahui 
gambaran secara mendalam hal yang berkaitan dengan penelitian. Menurut Nazir (1999) analisis deskriptif dapat menggambarkan sitasi yang tengah berlangsung baik dalam bentuk narasi, gambar maupun matriks.

Penelitian ini akan menggunakan Structural Equation Modelling (SEM) dalam pengolahan datanya. SEM merupakan analisis multivariate yang dapat menganalisis hubungan dengan banyak variabel secara meyeluruh. SEM sangat tepat digunakan untuk merancang penelitian manajemen serta menjawab pertanyaan yang bersifat regresif dan dimensional dalam waktu bersamaan. Regresif artinya pengujian antar konstruk, sedangkan dimensional artinya pengujian dimensi yang terdapat dalam konstruk (Hox J, 1995, 2007; Wijanto, 2015; Shook et al. 2004).
Analisis SEM akan diolah dengan software LISREL, dimana menurut Suharjo dan Suwarno (2002) LISREL sebagai analisis peubah ganda digunakan untuk mendeskripsikan keterkaitan anatara hubungan linear secara simultan peubah-peubah indikator baik peubah eksogen (X1-X15) maupun endogen (Y1-Y3) yang sekaligus melibatkan peubah-peubah latennya.

Pada Gambar 1 dapat dilihat indikator variabel laten eksogen yang digunakan untuk melihat efektivitas program kolokasi terbagi menjadi dua ( $\xi 1$ dan $\xi 2$ ) dalam dimensi Brand Awareness dan Responsiveness. Dari kedua variabel laten eksogen tersebut akan digunakan sebanyak 8 variabel indikator eksogen (X1.1 hingga $\mathrm{X} 2.5$ ) dan 3 variabel indikator endogen (Y1.1 hingga Y1.3), dengan pernyataan pada masing-masing variabel indikator pada Tabel 1.

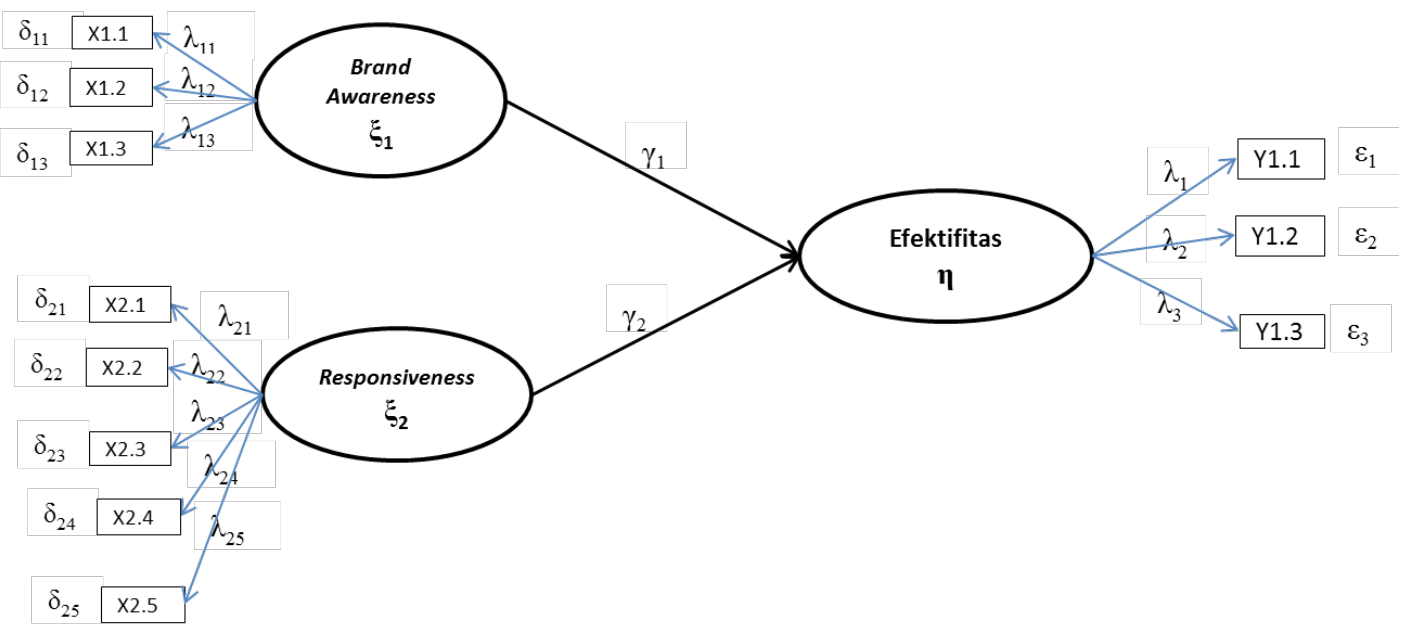

Gambar 1. Struktur Analisis SEM

Tabel 1. Variabel laten dan indikator model SEM

\begin{tabular}{|c|c|c|}
\hline Variabel laten & Indikator & Kode \\
\hline \multirow{3}{*}{$\begin{array}{l}\text { Efektivitas } \\
\quad(Y)\end{array}$} & 1. Saya mendapatkan pelayanan pembukaan rekening BNI Syariah di BNI cabang Dramaga & Y1 \\
\hline & 2. BNI cabang Dramaga bersedia melayani pergantian buku tabungan BNI Syariah & $\mathrm{Y} 2$ \\
\hline & $\begin{array}{l}\text { 3. Pegawai Bank BNI cabang Dramaga bersedia menanggapi semua keluhan nasabah BNI } \\
\text { Syariah }\end{array}$ & Y3 \\
\hline \multirow{3}{*}{$\begin{array}{c}\text { Brand } \\
\text { Awareness } \\
\text { (X1) }\end{array}$} & $\begin{array}{l}\text { 1. Saya mengetahui bahwa PT. Bank BNI Syariah merupakan anak perusahaan dari PT. Bank } \\
\text { BNI }\end{array}$ & $\mathrm{X} 11$ \\
\hline & 2. Saya mengetahui bahwa transaksi BNI Syariah dapat dilakukan di Bank BNI Konvensional & $\mathrm{X} 12$ \\
\hline & 3. Saya mengetahui mengenai program kolokasi BNI Syariah & $\mathrm{X} 13$ \\
\hline \multirow{5}{*}{$\begin{array}{l}\text { Responsiveness } \\
\quad \text { (X2) }\end{array}$} & 1. Pegawai Bank BNI cabang Dramaga memberitahukan mengenai jadwal pelayanan & $\mathrm{X} 31$ \\
\hline & 2. Pegawai Bank BNI cabang Dramaga memberikan pelayanan secara cepat & $\mathrm{X} 32$ \\
\hline & 3. Pegawai Bank BNI cabang Dramaga memberikan pelayanan secara tepat & $\mathrm{X} 33$ \\
\hline & 4. Saya mendapatkan sosialisasi program kolokasi selama bertransaksi di BNI Konvensional & $\mathrm{X} 34$ \\
\hline & $\begin{array}{l}\text { 5. Pegawai Bank BNI cabang Dramaga memberikan penjelasan yang mendetail mengenai } \\
\text { sosialisasi program kolokasi di BNI konvensional }\end{array}$ & $\mathrm{X} 35$ \\
\hline
\end{tabular}




\section{HASIL}

\section{Deskripsi Karakteristik Responden}

Nasabah yang terpilih sebagai responden dalam penelitian ini adalah nasabah BNI Syariah yang berkunjung ke BNI KLN IPB Dramaga dan BNI Syariah Cabang Bogor dengan memastikan terlebih dahulu bahwa frekuensi kunjungan ke BNI KLN IPB Dramaga minimal satu kali dalam sebulan. Responden terpilih memiliki usia berkisar antara 18-56 tahun dengan jumlah responden terbanyak pada kategori usia18-30 tahun sebanyak 221 responden. Selanjutnya, responden terpilih terdiri dari $57 \%$ berjenis kelamin laki-laki dan $43 \%$ berjenis kelamin perempuan dari total 370 responden. Pendidikan terakhir responden terbanyak berasal dari pendidikan D3 sebesar 37\%. Adapun pekerjaan pegawai swasta merupakan pekerjaan paling banyak yang dilakukan oleh responden sebesar 35,9\%, diikuti oleh mahasiswa sebesar $25,1 \%$. Karakteristik responden selengkapnya pada Tabel 2 .

\section{Analisis Model Pengukuran}

Analisis pengukuran model merupakan tahap untuk memastikan bahwa konstruk yang digunakan pada penelitian ini memenuhi kriteria valid dan reliabel (James et al. 2006; Pohlmann, 2004). Evaluasi terhadap model pengukuran dilakukan pada masing-masing variabel laten dengan melakukan pengujian validitas dan reliabilitas konstruk. Validitas merupakan instrumen yang digunakan untuk mengukur suatu kebenaran pengukuran. Dalam SEM, pengukuran validitas yakni menggunakan validitas konstruk untuk menjelaskan bahwa instrumen yang digunakan sudah mampu untuk mengukur konsep sebagaimana dikemukakan oleh teori. Pengukuran reliabilitas menunjukkan bahwa instrumen pengukuran adalah tidak bias sehingga menjamin pengukuran yang konsisten sepanjang waktu. Dikatakan suatu instrumen memiliki reliabilitas yang baik ketika jawaban responden untuk semua pertanyaan dalam sebuah konstruk konsisten (Sumarwan et al. 2015). Ukuran suatu indikator dikatakan valid jika memiliki nilai loading factor terhadap variabel laten yang ingin diukur $\geq 0,5$ dan memiliki nilai t-hitung $>$ 1,96 (Igbaria et al. 1997).

Berdasarkan Tabel 3, dapat dilihat bahwa semua variabel indikator memenuhi syarat validitas dengan ditunjukkan oleh nilai loading factor $\geq 0,5$ dan memiliki nilai t-hitung di atas 1,96. Hal ini mengindikasikan bahwa semua variabel indikator valid untuk mengukur konstruk latennya.Setelah pemeriksaan terhadap uji validitas model, kemudian tahap selanjutnya yaitu melihat konsistensi model dengan melakukan uji reliabilitas dengan menghitung nilai CR (Construct Reliability) dan VE (Variance Extracted). Suatu variabel dikatakan cukup konsistenapabila variabel tersebut mempunyai nilai $C R \geq 0,70$ dan nilai $\mathrm{VE} \geq 0,50$.

Berdasarkan hasil uji reliabilitas model pada Tabel 4 diperoleh uji reliabilitas secara keseluruhan sudah baik. Oleh karena itu, dapat disimpulkan bahwa indikator-indikator yang digunakan pada penelitian ini mempunyai reliabilitas yang baik atau mampu secara konsisten untuk mengukur konstruk latennya.

\section{Uji Kecocokan Keseluruhan Model}

Uji kecocokan model struktural secara keseluruhan dapat dilihat dari ukuran goodness of fit (GOf) (Hu dan Bentler, 1999; MacCallum et al. 1996; Sivo et al. 2006; Hooper et al. 2007). Suatu model dapat dikategorikan baik berdasarkan beberapa ukuran kriteria yaitu Root Mean Square (RMR), Adjusted Goodness of Fit Index (AGFI), Goodness of Fit Index (GFI), Root Mean Square Error of Approximation (RMSEA), Comparative Fit Index (CFI), Normed Fit Index (NFI) dan Relative Fit Index (RFI). Berikut adalah hasil uji kecocokan keseluruhan model dapat dilihat pada Tabel 5.

Tabel 2. Karakteristik responden

\begin{tabular}{lcc}
\hline \multicolumn{1}{c}{ Kategori } & Jumlah & Presentase (\%) \\
\hline Usia & & \\
18-30 tahun & 221 & 59,7 \\
31-42 tahun & 102 & 27,6 \\
43-56 tahun & 47 & 12,7 \\
Jenis kelamin & & \\
laki-laki & 211 & 57,0 \\
perempuan & 159 & 43,0 \\
Pendidikan terakhir & & \\
SMA & 126 & 34 \\
D3 & 136 & 37 \\
S1 & 104 & 28 \\
S2 & 4 & 1 \\
Pekerjaan & & \\
Mahasiswa & 93 & 25,1 \\
PNS/BUMN & 81 & 21,9 \\
Pegawai Swasta & 133 & 35,9 \\
Wiraswasta & 63 & 17,1 \\
\hline
\end{tabular}


Tabel 3. Uji validitas SEM

\begin{tabular}{ccccc}
\hline Variabel laten & Variabel indikator & Loading factor & T-hitung & Validitas \\
\hline Brand Awareness & X1.1 & 0,86 & 20,13 & Valid \\
& X1.2 & 0,65 & 13,78 & Valid \\
Responsiveness & X1.3 & 0,97 & 23,23 & Valid \\
& X2.1 & 0,87 & 18,56 & Valid \\
X2.2 & 0,94 & 20,06 & Valid \\
& X2.3 & 0,96 & 20,29 & Valid \\
X2.4 & 0,60 & 6,81 & Valid \\
Efektivitas & X2.5 & 0,93 & 19,71 & Valid \\
& Y1.1 & 0,77 & 7,32 & Valid \\
& Y1.2 & 0,68 & 7,57 & Valid \\
& Y1.3 & 0,91 & 12,44 & Valid \\
\hline
\end{tabular}

Tabel 4. Reliabilitas variabel laten SEM

\begin{tabular}{lcccc}
\hline \multicolumn{1}{c}{ Variabel Laten } & CR & Keterangan & VE & Keterangan \\
\hline Brand Awareness & 0,87 & Baik & 0,70 & Baik \\
Responsiveness & 0,94 & Baik & 0,76 & Baik \\
Efektivitas & 0,83 & Baik & 0,63 & Baik \\
\hline
\end{tabular}

Tabel 5. Hasil kriteria kecocokan keseluruhan model

\begin{tabular}{|c|c|c|c|}
\hline Goodness-of-Fit & Cut-off Value & Hasil & Kecocokan \\
\hline RMR (Root Mean Square Residual) & 0,05 atau 0,1 & 0,51 & Good fit \\
\hline RMSEA (Root Mean Square Error of Approximation) & 0,08 & 0,075 & Good fit \\
\hline GFI (Goodness of Fit) & 0,90 & 0,97 & Good fit \\
\hline AGFI (Adjusted Goodness of Fit Index) & 0,90 & 0,90 & Good fit \\
\hline CFI (Comparative Fit Index) & 0,90 & 0,99 & Good fit \\
\hline IFI (Incremental Fit Index) & 0,90 & 0,99 & Good fit \\
\hline NFI (Normed Fit Index) & 0,90 & 0,99 & Good fit \\
\hline RFI (Relative Fit Index) & 0,90 & 0,96 & Good fit \\
\hline
\end{tabular}

Berdasarkan Tabel 5, menunjukkan bahwa model SEM hasil modifikasi sudah fit atau sudah baik. Data hasil kuesioner sudah mampu menjawab teori yang dibangun. Beberapa kriteria yang menghasilkan kesimpulan model goodness of fit menunjukkan bahwa pengujian hipotesis teori dapat dilakukan.

\section{Analisis Model Struktural}

Model struktural dalam SEM adalah model yang menghubungkan variabel-variabel laten (laten eksogen dan laten endogen).Hasil pengujian hipotesis untuk model struktural pada penelitian ini dapat dilihat pada Tabel 6. Variabel laten eksogen dapat dikatakan berpengaruh terhadap variabel laten endogen ketika memiliki nilai t-hitung lebih dari 1,96.
Berdasarkan hasil pada Tabel 6, nilai t-hitung yang diperoleh dari hubungan antara variabel brand awareness dan responsiveness seluruhnya lebih dari 1,96. Pengaruh dari responsiveness terhadap efektivitas lebih dominan dibandingkan brand awareness, yaitu sebesar $(\gamma=0,39)$ (Tabel 6). Variabel responsiveness dijelaskan oleh 5 variabel indikator, dengan variabel X2.3 (Pegawai Bank BNI cabang Dramaga memberikan pelayanan secara tepat) memberikan kontribusi paling tinggi dalam pembentukan variabel responsiveness dengan nilai loading factor sebesar 0,96 (Gambar 2). Hal ini menunjukkan bahwa pelayanan yang diberikan oleh pegawai BNI KLN Dramaga kepada nasabah BNI Syariah telah sesuai dengan permintaan nasabah BNI Syariah. Sikap pegawai BNI konvensional cabang Dramaga yang melayani dengan tepat menggambarkan daya tanggap pegawai dalam kontribusinya 
menjalankan program kolokasi yang diterapkan BNI Syariah. Pelayanan pegawai BNI KLN Dramaga yang cepat kepada nasabah BNI Syariah juga menunjukkan bahwa komitmen BNI Konvensional yang tidak membedakan antara nasabah BNI konvensial dan BNI Syariah. Hal ini terlihat dari kontribusi yang signifikan dari X2.2 (Pegawai Bank BNI cabang Dramaga memberikan pelayanan secara cepat) dengan nilai loading factor sebesar 0,94 (Tabel 4).

Variabel X2.4 (Saya mendapatkan sosialisasi program kolokasi selama bertransaksi di BNI Konvensional) memberikan kontribusi yang signifikan. Namun, memiliki nilai factor loading yang tidak terlalu besar yaitu $(\lambda=0,60)$ terhadap responsiveness. Sosialisasi program kolokasi yang dilakukan oleh pegawai BNI KLN Dramaga tidak selalu terjadi ketika nasabah bertransaksi di BNI KLN Dramaga. Nasabah BNI Syariah yang melakukan transaksi di BNI KLN Dramaga juga sudah banyak yang mengetahui adanya program kolokasi BNI Syariah, hal ini dibuktikan dengan tingginya nilai kontribusi terhadap brand awareness yang signifikan dari variabel X1.3 (Saya mengetahui mengenai program kolokasi BNI Syariah) dengan nilai loading factor sebesar 0,97. BNI Syariah secara rutin juga membuka mobil layanan BNI Syariah diwilayah kampus IPB Dramaga sehingga sosialisasi program kolokasi juga dilakukan melalui mobil layanan tersebut.

\section{Pengaruh Brand Awareness BNI Syariah terhadap Efektivitas Program Kolokasi}

Hasil penelitian ini, usia responden terbanyak ada di rentan usia 18-30 tahun dan 31-42 tahun (Tabel 2) hal ini dikarenakan mayoritas dari responden adalah mahasiswa dan pekerja/karyawan disekitar kantor BNI Dramaga dan BNI Syariah Cabang Bogor. Dari hasil uji SEM, variabel X1 terdominan adalah responden mengetahui program kolokasi (variabel X1.3). Hal ini dikarenakan oleh upaya BNI Syariah yang telah terlebih dahulu melakukan sosialisasi kepada masyarakat khususnya di wilayah Dramaga melalui fasilitas mobil layanan atas program kolokasi. Ada tiga variabel indikator yang membentuk brand awareness ini yaitu mengetahui BNI Syariah merupakan anak perusahaan BNI (X1.1), mengetahui transaksi BNI Syariah dapat dilakukan di BNI (X1.2), dan mengetahui program kolokasi BNI Syariah (X1.3).

Tabel 6. Hasil pengujian hipotesis

\begin{tabular}{lcc}
\hline \multicolumn{1}{c}{ Hubungan kausalitas } & Koefisien jalur & T-hitung \\
\hline Brand awareness $\rightarrow$ efektivitas & 0,24 & 4,55 \\
Responsiveness $\rightarrow$ efektivitas & 0,39 & 7,22 \\
\hline
\end{tabular}

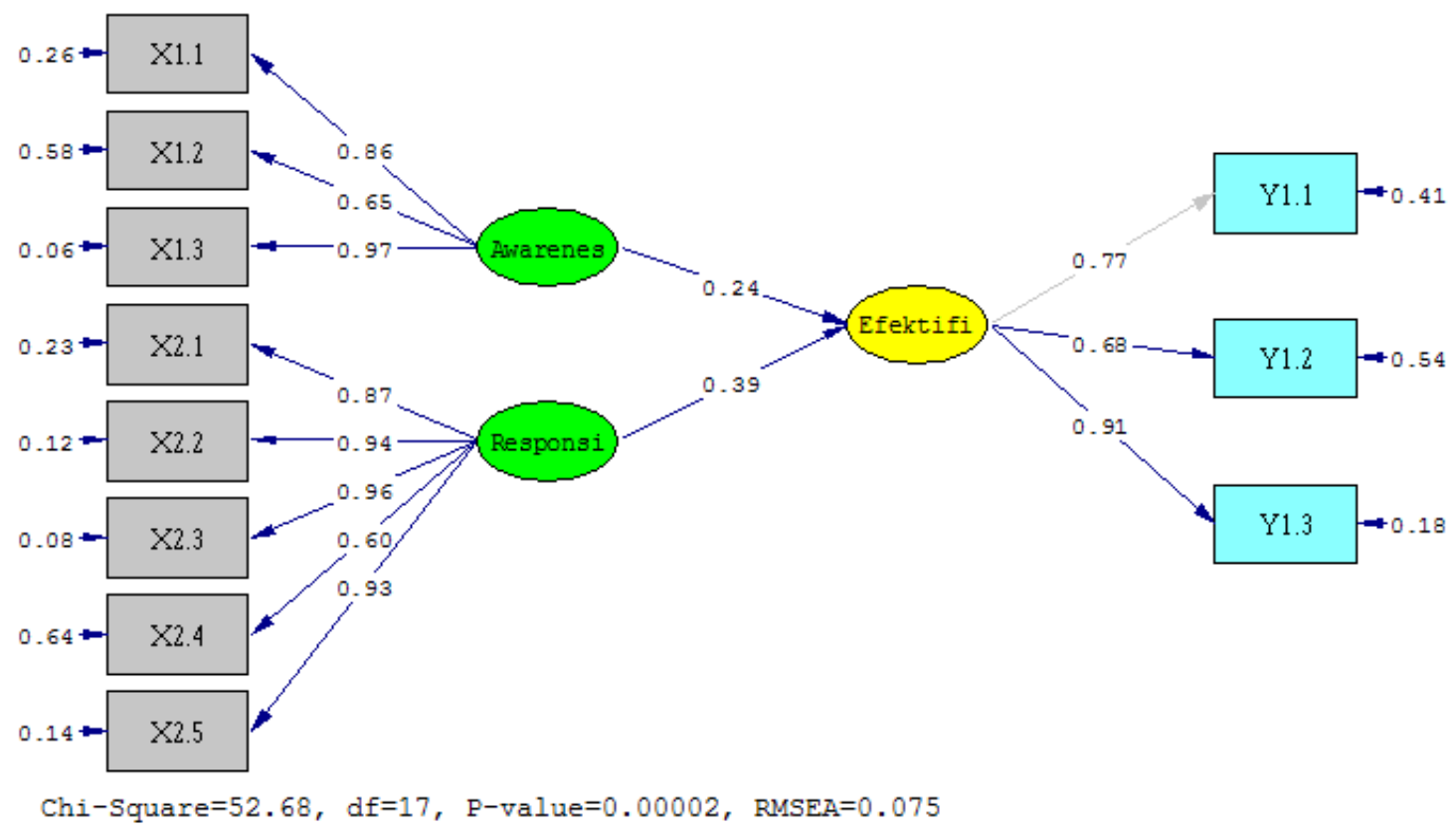

Gambar 2. Standardized loading factor SEM 
Identifikasi Variabel Indikator yang Dominan Membentuk Variabel Brand Awareness dan Variabel Responsiveness

Hasil uji SEM, variabel yang dominan membentuk brand awareness adalah X1.3 dan X1.1. Variabel X1.2 tidak menjadi yang dominan dikarenakan setelah terjadinya spinoff antara BNI dan BNI Syariah. Petugas layanan (customer service) tidak lagi memberikan informasi kepada masyarakat bahwa BNI Konvensional dapat menerima transaksi BNI Syariah. Petugas layanan BNI juga sering menolak untuk melayani transaksi BNI Syariah. Sehingga dibentuklah program kolokasi ini yang didalamnya juga ada program product knowledge BNI Syariah. Dengan adanya program ini, BNI Syariah menaruh harapan besar bahwa setelah adanya pelatihan kepada petugas layanan BNI Konvensional mereka akan mampu menjelaskan produk produk dari BNI Syariah kepada masyarakat. Variabel laten lainnya adalah responsiveness dimana ada lima variabel indikator yang membentuk responsiveness ini yaitu petugas BNI Dramaga memberitahukan jadwal layanan di IPB (X2.1), Petugas BNI memberikan pelayanan yang cepat (X2.2), Petugas BNI memberikan pelayanan yang tepat (X2.3), Petugas di BNI melakukan sosialisasi program kolokasi di BNI konvensional (X2.4), dan petugas BNI menjelaskan secara detail program kolokasi (X2.5). Dari hasil uji SEM ini, variabel X2.3 menjadi variabel yang dominan. Sedangkan variabel X2.4 dan X2.1 tidak menjadi variabel dominan dalam variabel responsiveness. Petugas BNI saatini dirasa masihenggan untuk menginformasikan kepada nasabah terkait produk syariah. Hal ini adalah salah satu alasan ditempatkannya petugas sales dari BNI Syariah di BNI IPB Dramaga. Dimana bila nasabah belum terinformasikan terkait program kolokasi ini, maka petugas sales dari BNI Syariah akan dapat langsung melayani kebutuhan informasi kepada nasabah. Petugas sales BNI Syariah yang ditempatkan di BNI IPB Dramaga juga berperan sebagai fasilitator dalam melakukan sosialisasi di BNI Konvensional. Variabel laten ketiga adalah efektivitas, ada tiga variabel indikator yaitu nasabah mendapat pelayanan pembukaan rekening BNI Syariah di BNI Dramaga (Y1.1), BNI Dramaga melayani proses ganti buku tabungan BNI Syariah (Y1.2) dan Petugas BNI Dramaga bersedia membantu semua keluahan nasabah BNI Syariah (Y1.3). dari hasil penelitian, variabel indikator Y1.3 adalah yang terdominan hal ini disebabkan oleh upaya yang dilakukan oleh BNI Syariah sebelum mengimplementasikan program kolokasi ini yaitu melakukan sosialisasi ke BNI
Konvensional mengenai BNI Incorporated, yaitu melihat BNI dan BNI Syariah sebagai satu kesatuan usaha. BNI Syariah juga secara bertahap melakukan refreshment kepada staf layanan BNI terkait produk Syariah. Serta penempatan petugas sales BNI Syariah di BNI Dramaga secara tidak langsung memengaruhi mulai dilayaninya nasabah BNI Syariah di BNI IPB Dramaga.

\section{Pengaruh Daya Tanggap (Responsiveness) Petugas Kolokasi di Kantor Layanan (KLN)}

Hasil penelitian menunjukan bahwa keputusan Management BNI Syariah dalam melakukan program kolokasi adalah tepat, karena selain meningkatkan sosialisasi perbankan syariah, program kolokasi juga berimplikasi pada meningkatnya brand awareness BNI Syariah. Masyarakat pada umumnya dan nasabah BNI syariah pada khususnya bisa mendapatkan informasi lebih tentang produk produk BNI Syariah di wilayah Dramaga. Selain itu, dengan meningkatnya brand awareness diharapkan dapat meningkatkan minat masyarakat untuk menggunakan perbankan syariah sebagai sarana transaksi perbankannya. Program Kolokasi yang baru diterapkan di KLN Dramaga ini dapat menjadi acuan bagi management BNI Syariah untuk dapat menempatkan petugas kolokasi di KLN BNI yang belum ada petugas kolokasinya. BNI Syariah dapat terus meningkatkan sosialisasi product knowledge BNI Syariah kepada petugas di KLN BNI dikarenakan sosialisasi yang dilakukan kepada petugas BNI berdampak atas lebih pahamnya mereka kepada produk produk BNI Syariah. Selain itu BNI Syariah juga perlu untuk meningkatkan responsiveness dalam pelayanan nasabah.

Pengetahuan serta kemampuan petugas kolokasi dalam membantu menyelesaikan permasalahan yang timbul dalam transaksi nasabah menjadi salah satu indikator keberhasilan efektivitas program kolokasi. Program kolokasi ini juga secara tidak langsung menimbulkan kesinergian antara BNI dan BNI Syariah dilini bawah yaitu di lini layanan. Petugas layanan BNI secara tidak langsung mengetahui program ini dan dapat melayani nasabah BNI Syariah di BNI konvensional. BNI Syariah juga bisa mengetahui terkait responsiveness petugas kolokasi, BNI Syariah harus bisa memastikan bahwa setiap petugas layanan dapat menyampaikan program kolokasi kepada nasabah yang datang ke BNI IPB Dramaga. Setelah adanya program kolokasi ini petugas layanan di BNI, dari hasil penelitian ini, 
sudah menunjukkan respons positif dalam menanggapi keluhan nasabah BNI Syariah. Hal ini menunjukan adanya peningkatan mutu layanan dari BNI Syariah terhadap nasabahnya melalui program kolokasi ini.

\section{Implikasi Manajerial}

Implikasi Menejerial yang bisa disimpulkan dari penelitian ini adalah program kolokasi ini harus diteruskan dikarenakan telah berhasil mendorong perbaikan layanan dan juga terinformasikannya perbankan syariah. Manajemen BNI Syariah perlu melakukan upaya sosialisasi secara berkesinambungan agar program ini terus bertahan.

\section{KESIMPULAN DAN SARAN}

\section{Kesimpulan}

Program kolokasi adalah program yang sengaja dibentuk untuk bisa meningkatkan pelayanan syariah khususnya BNI Syariah melalui kantor layanan BNI Konvensional.Selainitu,BNISyariahjugamenempatkan pegawainya dilokasi kolokasi yang ditunjuk untuk memastikan program berjalan dengan baik. Dari hasil penelitian ini, dapat disimpulkan dari Variabel laten yang telah penulis identifikasi, terdapat variabel indikator dari masing masing variabel laten. Pada Variabel Brand awareness (X1) terdapat tiga variabel indikator yaitu saya mengetahui bahwa PT Bank BNI Syariah merupakan anak perusahaan dari PT Bank BNI (X1.1), Saya mengetahui bahwa transaksi BNI Syariah dapat dilakukan di Bank BNI Konvensional (X1.2), dan saya mengetahui mengenai program kolokasi BNI Syariah (X1.3). Pada Variabel responsiveness (X2) terdapat lima variabel indikator yaitu Pegawai Bank BNI Cabang Dramaga memberitahukan mengenai jadwai pelayanan syariah di IPB (X2.1), Pegawai Bank BNI Cabang Dramaga memberikan pelayanan secara cepat (X2.2), Pegawai Bank BNI Cabang Dramaga memberikan pelayanan secara tepat (X2.3), nasabah mendapatkan sosialisasi program selama bertransaksi di BNI Konvensional (X2.4), dan pegawai Bank BNI Cabang Dramaga memberikan penjelasan yang mendetail mengenaia program kolokasi di BNI Konvensional (X2.5). Variabel laten lain adalah Efektivitas (Y) dimana terdapat tiga variabel indikator, yaitu nasabah mendapatkan pelayanan pembukaan rekening BNI Syariah di BNI Dramaga (Y1.1), BNI Cabang Dramaga bersedia melayani pergantian buku tabungan BNI Syariah (Y1.2), dan Pegawai Bank BNI Cabang Dramaga bersedia menanggapi semua keluhan nasabah BNI Syariah (Y1.3).

Program kolokasi dinilai sangat positif dan efektif dalam meningkatkan efektivitas sosialisasi Perbankan syariah yang dilaksanakan oleh BNI Syariah. Brand awareness berpengaruh positif pada efektivitas program kolokasi yang dilakukan oleh BNI Syariah Cabang Bogor. Dari Hasil penelitian, variabel indikator yang paling berkontribusi dalam pembentukan variabel brand awareness adalah variabel X1.3 (Saya mengetahui program kolokasi BNI Syariah).

Dari segi responsiveness, petugas kolokasi dengan pengetahuan produk yang mumpuni serta daya tanggap yang baik dalam mensosialisasi produk BNI Syariah dan problem solving permasalahan yang dihadapi nasabah merupakan salah satu hal yang menunjang keberhasilan efektivitas sosialisasi yang dilakukan oleh BNI Syariah. Dari hasil penelitian ini terdapat pengaruh signifikan dan positif dari petugas kolokasi terhadap efektivitas program ini.

Dari lima variabel yang membentuk responsiveness, yaitu pegawai Bank BNI cabang Dramaga memberitahukan mengenai jadwal pelayanan, pegawai Bank BNI cabang Dramaga memberikan pelayanan secara cepat, pegawai Bank BNI cabang Dramaga memberikan pelayanan secara tepat, saya mendapatkan sosialisasi program kolokasi selama bertransaksi di BNI Konvensional, pegawai Bank BNI cabang Dramaga memberikan penjelasan yang mendetail mengenai sosialisasi program kolokasi di BNI konvensional. Variabel paling dominan membentuk variabel responsiveness adalah Pegawai Bank BNI cabang Dramaga memberikan pelayanan secara tepat.

\section{Saran}

Dalam penelitian ini, penulis membahas mengenai program kolokasi di BNI IPB Dramaga, program kolokasi saat ini telah berjalan diseluruh BNI di Indonesia sehingga diperlukan penelitian lebih lanjut sejauh mana efektivitas dari program ini. Dikarenakan keterbatasan waktu, untuk penelitian selanjutnya sempat membahas mengenai implikasi program kolokasi terhadap peningkatan DPK di SCO. Dari hasil penelitian ini, BNI Syariah perlu menambah jumlah petugas kolokasi di setiap KLN BNI serta BNI Syariah dapat membuka kantor cabang nya sendiri di Dramaga. 


\section{DAFTAR PUSTAKA}

Hu LT, Bentler PM. 1999. Cut off criteria for fit indices in covariance structure analysis: Conventional criteria versus new alternatives. Structural Equation Modeling. Journal of American Psychological Associaton 6(1): 1-55.

Hooper D, Coughlan J. Mullen MR. 2007. Structural equation modelling: guidelines for determining model fit. Journal on Business Research Methods 6(1):53-60.

Hox JJ. 1995. Amos, eqs, and lisrel for windows: A comparative review. Structural Equation ModelingAMultidisciplinaryJournal2(1):79-91. https://doi.org/10.1080/10705519509539996.

Hox JJ. 2007. An Introduction to structural equation modeling. Family Science Review Journal 11(1): 354-373.

Igbaria M, Zinatelli N, Cragg P, Cavaye ALM. 1997. Personal computing acceptable factors in small firms: a structural equation model. MIS Quarterly 21(3): 279-299. https://doi.org/10.2307/249498.

James BS, Amaury N, Frances KS, Elizabeth A. Barlow JK. 2006. Reporting structural equation modeling and confirmatory factor analysis results: a review. The Journal of Educational Research. 99(6):323338.https://doi.org/10.3200/JOER.99.6.323338.

MacCallum RC, Browne MW, Sugawara HM. 1996. Power analysis and determination of sample size for covariance structure modeling psychological methods. Journal of American Psychological Associaton 1(2):130-149.
Pohlmann JT. 2004. Use and interpretation of factor analysis in the journal of educational research: 1992-2002. The Journal of Educational Research 98(1): 14-22. https://doi.org/10.3200/ JOER.98.1.14-23.

Shook CL, Ketchen DJ, Hult GTM, Kacmar M. 2004. An assessment of the use of structural equation modeling in strategic management research. Strategic Management Journal 25(4): 397-404. https://doi.org/10.1002/smj.385.

Sivo SA, Xitao F, Witta EL, Willse JT. 2006. The search for "optimal" cutoff properties: Fit index criteria in structural equation modeling. Journal of Experimental Education 74(3): 267-288. https:// doi.org/10.3200/JEXE.74.3.267-288.

Suharjo B, Suwarno. 2002. Model Persamaan Structural, Teori dan Aplikasinya. Bogor: IPB Press.

Sumarwan U, Daryanto A, Achsani NA, Fahmi I, Nuryartono N, Suhendi, Lindiasari P, Sijabat FDV, Tobing A, Kristiadi A, Hardiyanto AT, Mumbuna C, Herdiawan D, Efendi, Nuraini E, Susilowati E, Ekyawan F, Devi HL, Fatimah H, Pujiyono J, Ong L, Dachyar M, Bariah N, Sitorus PM, Raharjo PG, Silitonga P, Sukardi PI, Srihadi RF, Riandarini RH, Tarigan RE, Rahardja SB, Hannan S, Sugiharto, Suhartono, Johan S, Immawan T, Yoyo T. 2015. Metode Riset Bisnis dan Konsumen. Bogor: IPB Press.

Wijanto SH. 2015. Metode Penelitian menggunakan Structural Equation Modeling dengan LISREL 9. Jakarta: Lembaga Penerbit Fakultas Ekonomi Universitas Indonesia. 